\title{
Amniotic band attached to fetal head - a rarest site of amniotic band presentation causing umbilical cord strangulation and fetal demise: case report
}

\author{
${ }^{1}$ Vaibhav Kanti, ${ }^{2,}$ Prashant kumar Mishra, ${ }^{3,}$ Rajani Rawat, ${ }^{4,}$ Neelam \\ swaroop, ${ }^{5}$ Pragati Mishra, ${ }^{6}$ Priya Sharma \\ 1,3,4,5,6-Department of obstetrics and gynaecology, UPRIMS \&R Saifai, Etawah \\ 2-Department of anesthesia,UPRIMS\&R,Saifai,Etawah \\ Correspondence: Dr.Vaibhav Kanti, C-102,type-4 ,new campus,Saifai,Etawah-206130
}

\begin{abstract}
Amniotic band syndrome is an uncommon pathological condition that can lead to intrauterine fetal demise. We report an unusual case of amniotic band presentation attached to fetal head in which umbilical cord got strangulated and resulted to fetal loss.
\end{abstract}

Key Words: amniotic band syndrome, umbilical cord, strangulation

\section{INTRODUCTION}

Amniotic band syndrome is an uncommon congenital pathological condition that may lead to malformation and fetal death.Strands of amniotic sac ensnares parts of fetal developing body parts leading to several problems. Amniotic bands occur in 1 of every 1,200-15,000 births and are demonstrable in $1-2 \%$ of malformed infants [1].Nearly $10 \%$ of cases include umbilical cord strangulation [2].Here we report an unusual case of amniotic band syndrome were the amniotic band was attached to fetal head and the twisting of umbilical cord around this fibrous band lead to decrease fetal movement,fetal distress ultimately leading to fetal demise in second trimester, at 23 weeks.

\section{CASE REPORT}

A 33-year- old registered G2P0A1 presented with decreased fetal movement at 23 weeks of gestation,carrying a level II USG,detecting no congenital anomaly.

She had previous one miscarriage at 9 weeks of gestational age not followed by D\&C.

There was history of hypothyroidism for which she was already taking thyroxine 50microgram daily.On examination: fundal height was 22-24 weeks, FHS could not be localised with stethoscope therefore an urgent USG was done and FHR was found to be 50-60 beats /min, which got disappeared within 2-3 minutes.

Termination of pregnancy was done with prostaglandin E2 and a $560 \mathrm{gm}$ still born, female embryo was delivered along with placenta in toto .On examination of the fetus a band of membrane measuring $4.5 \mathrm{~cm}$ in length was found between placenta and fetal scalp (parieto-temporal junction of foetal skull).The umbilical cord was found to be entangled to the band. CRL (crown rump length) was $22 \mathrm{~cm}$. The placenta weighted $210 \mathrm{gm}$ and measured $13 \times 8 \times 3 \mathrm{~cm}$, while umbilical cord measured $32 \mathrm{~cm}$ and its architecture was normal with three vessels.

\section{DISCUSSION}

Amniotic constriction band was first described by Montgomery in 1832 .

Although there are many theories, like the intrinsic model proposed by George streeter in 1930,vascular theory proposed by Van Allen in 1981 but the most widely accepted theory, the extrinsic model was proposed by Torpin in 1965 who suggested that early amnion rupture might be the cause[3]. The most common problems that are associated with amniotic band syndrome are cleftlip/palate and clubed foot.Associated anomalies may occur in approximately in 40-60\% of cases.Usually there are no abnormalities of internal organs. Prevalence varies depending upon whether the abortions secondary to ABS have been figured or not.It is believed to be the cause of 178 in 10000 abortions. ABS is more commanly present among African Americans as compared with Caucasians [4].ABS occurs randomly, it is not genetic, with amniotic banding no two cases are alike.

Only rare cases of intrauterine foetal death by constriction of the umbilical cord have been described in literature,mostly in the second and third trimester $[5,7]$

The incidence of intrauterine fetal death from ABS involving umbilical cord is not known but a number of cases have been reported(Graf et al.1997;kanayama etal.1995;Torpin1965).Constriction of umbilical cord is very rare and as in our case, the site of presentation being rarest may lead to extreme difficulty in making diagnosis by antenatal sonography. Antenatal diagnosis of ABS is frequently difficult and is accurately 
diagnosed in only $29 \%$ to $50 \%$ of cases [6]. Once diagnosed sonographically,umbilical cord constriction may be amenable to foetoscopic release in an attempt to avert fetal death. Fetoscopic release of umbilical cord amniotic band using YAG laser fibre has been reported[2].

\section{REFERENCES:}

[1]. Garza A, Cordero JF, Mulinare J. Epidemiology of the early amnion rupture spectrum of defects. Am J Dis Child1988; 142: 541544

[2]. Peiro JL,Carreras E,Soldado F,Sanchez-Duran MA:Fetoscopic release of umbilical cord amniotic band in human fetus:Ultrasound Obstet Gynecol.2009 Feb;33:232-234.

[3]. Torpin R Amniochorionicmesoblastic fibrous rings and amniotic bands:associated constricting fetal malformations or fetal death.Am J ObstetGynecol1965;91:65-75.

[4]. Goldfarb CA, Sathienkijkanchai A, Robin NH. Amniotic Constriction Band: A Multidisciplinary Assessment of Etiology and Clinical Presentation. J Bone Joint Surg Am. 2009; 91 Suppl 4: 68-75

[5]. Reles A, Friedmann W, Vogel M, Dudenhausen J:Intrauterine fetal death after strangulation of umbilical cord by amniotic band.Geburtshilfe Frauenheilkd1991,51:1006-1008.

[6]. Chandran S, Lim MK, Yu VY. Fetalacalvaria with amniotic band syndrome. Arch Dis Child Fetal Neonatal Ed 2000; 82, F11F13

[7]. Lurie S, Feinstein M, Mamet Y:Umbilical cord strangulation by an amniotic band resulting in a stillbirth: J Obstet Gynaecol Res $, 34: 255-257$

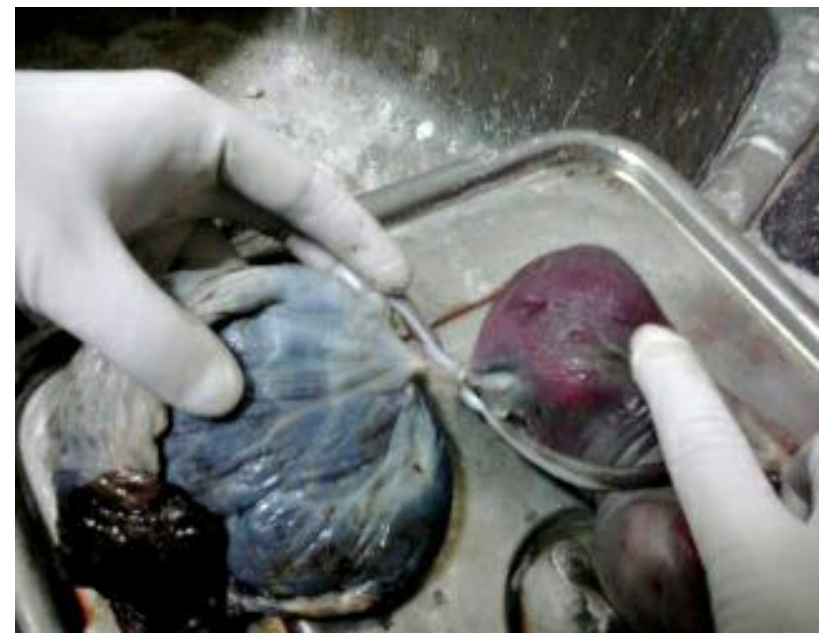

Figure 1.cord entangled between the fibrous band

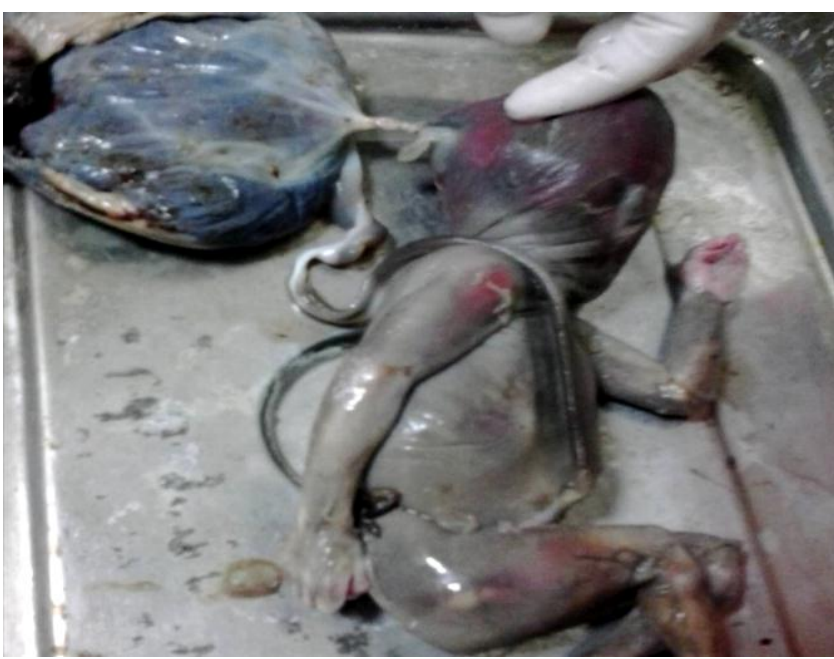

Figure2: fibrous band after separation of umbilical cord. 